\title{
Grandparent Support for Mothers of Children With and Without Physical Disabilities
}

\author{
Ineke M. Pit-ten Cate, Richard P. Hastings, Hannah Johnson, \& Sara Titus
}

\begin{abstract}
Grandparents' support to families of children with disabilities is generally associated with improved parental well-being. Little research addresses the question of quantitative differences in grandparent support to families of children with and without disabilities. This article examines such differences. Data was collected on 50 mothers of children with spina bifida and 43 mothers of children without disabilities and results showed how mothers rated perceived maternal and paternal grandparent support. No differences were found between mothers of children with and without disabilities. These results confirm previous findings that grandparent support appears to be no more frequent in families of children with disabilities than in other families. These findings are discussed with reference to sampling limitations and implications for further research.
\end{abstract}

G randparents of children with disabilities have been receiving increased research attention in recent years (Hastings, 1997; Sandler, 1998). One reason for this is that there appears to be a growing general trend for grandparents to adopt parenting roles, especially for children with special needs or when parents are unable to fulfill the role themselves for some reason (e.g., FullerThomson, Minkler, \& Driver, 1997; Grant, 2000; Mayer, 2002). A second reason for the interest in grandparents of children with disabilities is that they are likely to be a significant source of support for parents raising children with disabilities. Researchers have shown that grandparents provide a broad range of practical (e.g., shopping, household chores, baby-sitting or having grandchildren to stay overnight, providing financial support, and assisting with therapeutic tasks) and emotional (e.g., being available to discuss problems, making regular telephone contact) sup- port to parents of children with disabilities (Baranowski \& Schilmoeller, 1999; Findler \& Taubman-Ben-Ari, 2003; Gardner, Scherman, Mobley, Brown, \& Schutter, 1994; Hornby \& Ashworth, 1994; Scherman, Gardner, Brown, \& Schutter, 1995; Trute, 2003; Vadasy, Fewell, \& Meyer, 1986). Support from grandparents is not available equally to all families of children with disabilities. Rather, maternal grandparents typically provide more support than paternal grandparents; grandmothers typically provide more support than grandfathers; grandparents living closer to the family of the child with disability typically provide more support than those who live a greater distance away; and grandparents with higher levels of education may provide more support (e.g., Glasberg \& Harris, 1997; Hornby \& Ashworth, 1994; Schilmoeller \& Baranowski, 1998; Seligman, Goodwin, Paschal, Applegate, \& Lehman, 1997; Trute, 2003). Furthermore, the results of recent qualitative 
studies have suggested that preexisting positive relationships between parents and grandparents have a strong positive association both with the amount of support grandparents provide after the birth of a child with disabilities and with ongoing positive family interaction (Mirfin-Veitch, Bray, \& Watson, 1996, 1997; Nybo, Scherman, \& Freeman, 1998).

Several studies have found that the support from grandparents has positive effects for parents, especially in regards to the reduction of parental stress. Two studies have shown beneficial effects for fathers of children with disabilities, but not for mothers. Specifically, fathers' beliefs about the future were more positive (Waisbren, 1980) and stress levels were lower (Sandler, Warren, \& Raver, 1995) when grandparents provided more support, but mother adaptation was not affected. However, other data do suggest that mothers might also benefit from grandparent support. For example, Heller, Hsieh, and Rowitz (2000) found that younger mothers of children with intellectual disabilities who had poor physical health and less emotional support from grandparents were most at risk for depression. Similarly, Hastings, Thomas, and Delwiche (2002) found that stress in mothers of children with Down syndrome was lower when grandparents provided more instrumental and emotional support. Finally, other research has found that both mothers and fathers might benefit from grandparent support in terms of reduced stress and depression, but that this may be specific to support from their own mothers (Trute, 2003).

Although grandparents seem to play a key role in providing support to families of children with disabilities, and this support might benefit parental well-being, we could find only one previous study (Findler, 2000) that explored whether the support available to such families is similar to or different from that found in families of children without disabilities. This is an important question to help us better understand the support networks of families of children with disabilities (Hastings, 1997) and consider the implications for grandparent well-being. Findler (2000) studied Israeli mothers of children with cerebral palsy and mothers of children without disabilities. No group differences were found, but there was a replication of the finding that maternal grandmothers provided the most support and that mothers were most satisfied with the support provided by their own mothers. The purpose of the present study was to partially replicate Findler's (2000) research.

\section{Method}

\section{Procedure}

Mothers in the spina bifida sample were recruited from the Child Health and Development Study (CHADS; see Pitten Cate, Kennedy, \& Stevenson, 2002; Stevenson \& Pit-ten Cate, 2003). As part of CHADS, 553 families of children with spina bifida and/or hydrocephalus completed an extensive survey regarding the developmental, behavioral, and educational characteristics of children with spina bifida and hydrocephalus. This initial sample was recruited in 1999 through the register of the Association for Spina Bifida and Hydrocephalus (ASBAH). ASBAH serves the geographical area of England, Wales, and Northern Ireland, and families are entered on this register when they contact ASBAH for information and/or support. The current sample included families of children with spina bifida meningocele and myelomeningocele with or without hydrocephalus who indicated they could be contacted for future research. Mothers $(n=136)$ received written invitations to participate in the research. One set of postal reminders was issued, and after a 3-month period, 57 questionnaires were received, representing a response rate of $42 \%$. However, for seven mothers, data were incomplete, which reduced the number of respondents included in the analyses to 50. Mothers of children without disabilities were recruited by asking the mothers of children with spina bifida to distribute a questionnaire about grandparent support to a friend who had a child of a similar age to their own. Forty-three friends of mothers of children with spina bifida participated in the research (75\%).

This recruitment method for the control sample was chosen to improve the socioeconomic match between the disability and control groups. Chi-square analyses and ttests were conducted to test for demographic differences between the two groups. No significant differences were found for child's age, mother's age, the number of people living at home, child gender, family constellation, or mother's and father's employment status (Table 1 and 2).

\section{Participants}

Fifty mothers of children with spina bifida participated in the study. Children's ages ranged 8 to 15 years, and ages of mothers ranged from 28 to 54 years. Spina bifida type included spina bifida meningocele (16\%) and myelomeningocele (84\%). Most children had their lesion in the lumbar region (64\%); 6 children had higher lesions; and 11 children lower lesions. Thirty-eight children (76\%) with spina bifida also suffered from hydrocephalus. All children suffered to some degree functional limitations. There were no differences between the spina bifida

TABLE 1. Descriptive Statistics and $t$-Values for Demographic Variables

\begin{tabular}{|c|c|c|c|c|c|c|c|}
\hline \multirow[b]{2}{*}{$t$-TEST } & \multicolumn{3}{|c|}{ SPINA BIFIDA Group } & \multicolumn{3}{|c|}{ CONTROL GROUP } & \multirow[b]{2}{*}{$t$} \\
\hline & MeAN & $S D$ & N & MEAN & $S D$ & N & \\
\hline Age, child & 11.14 & 2.00 & 50 & 11.12 & 2.01 & 43 & .06 \\
\hline Age, mother & 38.98 & 5.73 & 50 & 39.72 & 5.57 & 43 & -.63 \\
\hline $\begin{array}{l}\text { Number of } \\
\text { people living }\end{array}$ & & & & & & & \\
\hline at home & 4.38 & .99 & & 4.58 & 1.14 & & -.91 \\
\hline
\end{tabular}


TABLE 2. Descriptive Statistics and Chi-Square Statistics for Demographic Variables

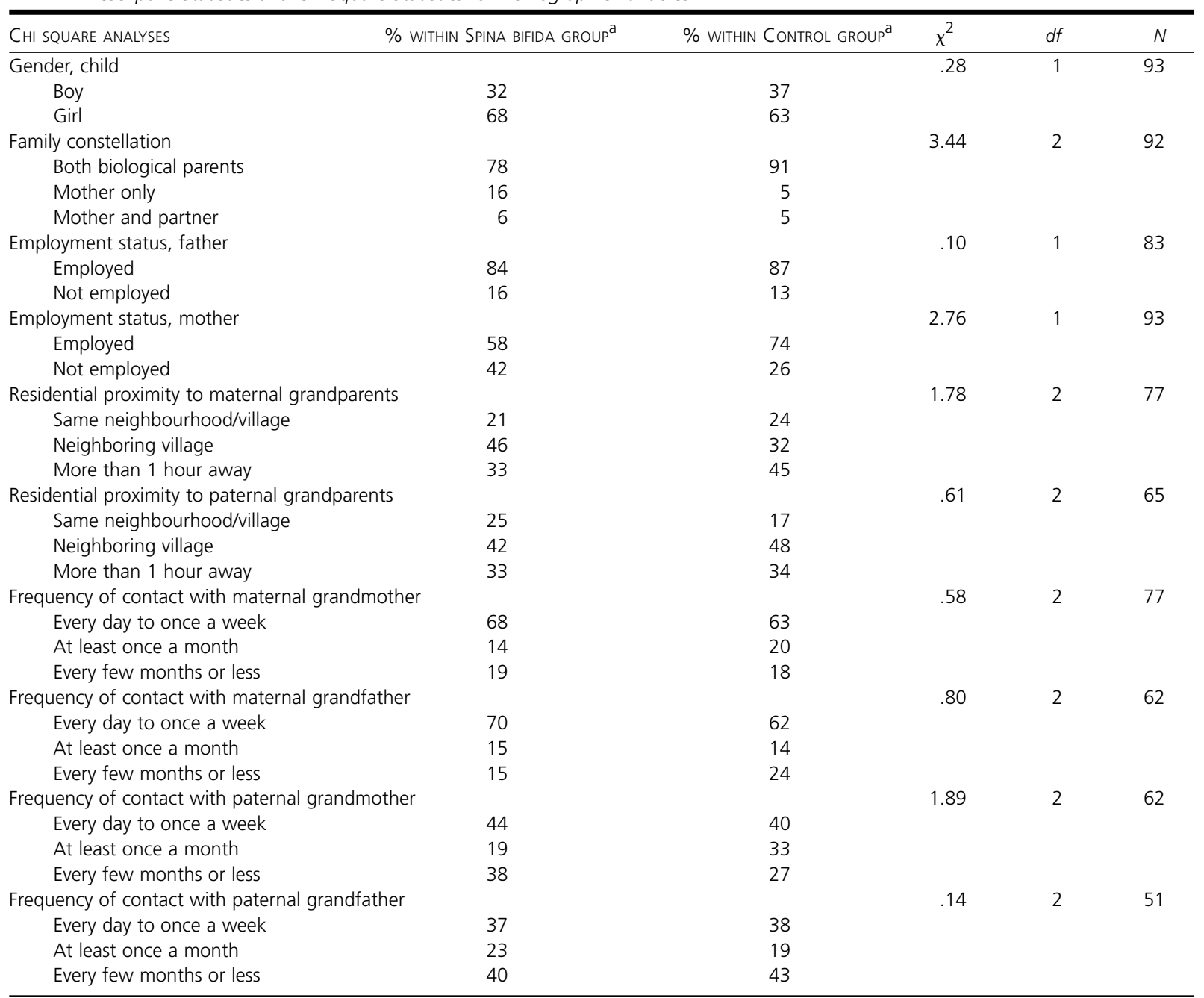

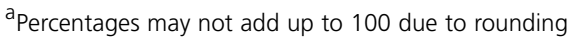

meningocele and myelomeningocele groups on measures of functional limitations or severity in terms of ability to walk, urinary and bowel function, weight, and the occurrence of pressure sores. Forty-three mothers of children without disabilities also participated in the study. Ages of children in the control group ranged from 7 to 15 years, and mothers' ages ranged from 29 to 50 years. Further demographic characteristics are in Tables 1 and 2.

\section{Social Support Measure}

Mothers were asked to complete the 12-item short form of the Support Functions Scale (SFS; Dunst, Trivette \& Deal, 1996). Support functions that were assessed include practical items (e.g., "someone to help take care of my child"; "someone to help with household chores"), and emotional support functions (e.g., "someone to talk about things that worry me"; "someone to keep me going when things seem hard"). The instructions for this scale were amended such that each item was completed in terms of the frequency of support provided by the child's grandparents. Frequency of support was assessed on a 5-point scale from "never" to "very often." A separate scale was completed for each set (maternal and paternal) grandparents. Mothers were asked to consider how frequently, for example, their own parents fulfilled each of the support functions listed.

Using Cronbach's alpha coefficient, the internal consistency of this scale was assessed based on a total support scale derived from the summed scores on all 12 items (minimum score possible $=12$, maximum score possible $=60$ ). . Reliability was assessed separately for mothers' ratings of maternal and paternal grandparents and separately by disability group. The alpha values obtained (range .89-.92) supported the reliability of the scale for control and spina bifida samples and for use with maternal and paternal grandparents.

\section{Results}

The total scores on the SFS were tested using one-sample Kolmogorov-Smirnov analyses to establish their suitability for parametric statistical analyses. These tests revealed that all 
of the scores were not significantly different from a normal distribution. We conducted a 2 (disability group) $\times 2$ (grandparent group-maternal vs. paternal) repeated measures analysis of variance to explore differences in grandparent support within and between disability groups. Descriptive statistics and $F$ values are reported in Table 3.

The repeated measures analysis of variance showed that ratings of maternal grandparent support were significantly higher than ratings of paternal grandparent support for mothers in both the spina bifida and control samples. However, there was no difference between disability groups in ratings of maternal or paternal grandparent support.

We conducted additional multivariate analyses of variance to test for differences between groups on the individual items of the SFS for maternal and paternal grandparents. The most common type of support provided by all four grandparents for both mothers of children with and without spina bifida was "accepts grandchild regardless." For grandmothers, the most common types of assistance further included "someone to relax with," "someone to talk to about worries," "does things with grandchild," and "helps me keep going when things get hard." For grandfathers, further types of assistance included "someone to relax with," "someone to talk to about worries," and "helps to take care of grandchild." This pattern of responses indicates that mothers of children with or without spina bifida receive mostly emotional support from respective grandparents. No significant differences between groups were found in terms of type of support provided by maternal or paternal grandparents (Wilks $\lambda=.78, F(12,72$ ) $=1.65 \mathrm{~ns}$, and Wilks $\lambda=.90, F(12,61)=.54 \mathrm{~ns}$, respectively).

Pearson correlations were computed to investigate the associations between child variables (age and disability characteristics), residential proximity, and frequency of contact and perceived grandparent support. Both child age and frequency of contact were associated with grandparent support. More frequent contact with both grandmother and grandfather was associated with more perceived support for both maternal and paternal grandparents (Pearson correlations ranged from -.29 to -.56 ). More perceived parental grandparent support was reported when the grandchild was younger $(r=-.26)$. No such relationship was found for
TABLE 4. Summary of Simultaneous Hierarchical Regression Analyses for Independent Variables Predicting Grandparent Support

\begin{tabular}{|c|c|c|c|}
\hline DV & B SE & B & $\beta$ \\
\hline \multirow{4}{*}{$\begin{array}{l}\text { Maternal SPS age, grandchild } \\
\text { Residential proximity } \\
\text { Frequency of contact, } \\
\text { grandmother } \\
\text { Frequency of contact, } \\
\text { grandfather }\end{array}$} & -.23 & .46 & -.05 \\
\hline & 3.92 & .98 & $.49 * * *$ \\
\hline & -2.90 & .57 & $-.59 * * *$ \\
\hline & -1.31 & .43 & $-.33^{* *}$ \\
\hline \multirow{4}{*}{$\begin{array}{l}\text { Paternal SPS age, grandchild } \\
\text { Residential proximity } \\
\text { Frequency of contact, } \\
\text { grandmother } \\
\text { Frequency of contact, } \\
\text { grandfather }\end{array}$} & -.79 & .36 & $-.20^{*}$ \\
\hline & .84 & .61 & .14 \\
\hline & -1.86 & .39 & $-.50 * * *$ \\
\hline & -1.24 & .34 & $-.35^{* * *}$ \\
\hline
\end{tabular}

${ }^{*} p<.05 * * p<.01 * * * p<.001$

maternal grandparent support $(r=-.09)$. Residential proximity to paternal grandparents was associated with perceived support from both maternal and paternal grandparents ( $r=$ -.30 and $r=-.22$ respectively). No differences between groups were found for these variables (see Table 1 and 2). Child age, frequency of contact, and residential proximity together explained $36 \%$ and $47 \%$ of the variance in maternal and paternal grandparent support respectively (Table 4).

Significant predictors of maternal grandparent support included residential proximity and frequency of contact with both maternal grandparents, while paternal grandparent support was associated with the grandchild's age and frequency of contact with both paternal grandparents.

\section{Discussion}

The results of the present research support the general findings reviewed in the Introduction-maternal grandparents provide more support to mothers than do paternal grandparents. However, consistent with Findler's (2000) study, there were no effects of child disability. Although there are a number of limitations with the present study, there is consistent evidence that grandparents provide no more support to mothers of children with physical disabilities than they do to mothers of children without disabili-

TABLE 3. Repeated Measures Analysis of Variance for Grandparent Support (GPS)

\begin{tabular}{|c|c|c|c|c|c|c|}
\hline \multirow[b]{2}{*}{ VARIABLE } & \multicolumn{3}{|c|}{ SPINA BIFIDA GROUP } & \multicolumn{3}{|c|}{ CONTROL GROUP } \\
\hline & $n$ & MEAN & $S D$ & $n$ & MEAN & $S D$ \\
\hline Maternal grandparents support & 38 & 32.18 & 10.11 & 31 & 33.81 & 10.01 \\
\hline \multirow[t]{2}{*}{ Paternal grandparents support } & 38 & 22.95 & 8.21 & 31 & 22.90 & 7.38 \\
\hline & MS & $D F$ & $F$ & & & \\
\hline Between subjects factor: Group & 21.26 & 1 & .23 & & & \\
\hline Between subjects error & 92.48 & 67 & & & & \\
\hline Within subject factor: GPS & 3462.49 & 1 & $49.16^{*}$ & & & \\
\hline Within subjects error & 70.43 & 67 & & & & \\
\hline Interaction: GPS $\times$ Group & 23.70 & 1 & .34 & & & \\
\hline
\end{tabular}

${ }^{*} p<.001$ 
ties. In addition, there were no differences in type of support each group received. More specifically, mothers of children with and without disabilities received mainly emotional support from both maternal and paternal grandmothers and grandfathers, although some practical support in looking after the child was received as well. This finding was somewhat surprising, as previous research has indicated differences in grandparent support with grandmothers providing mainly emotional support and grandfathers instrumental support (e.g., Baranowski \& Schilmoeller, 1999). Only a few mothers reported that they received help in obtaining information or assistance with regard to services related to the child's disability. Thus, despite perhaps more support needs, grandparents may not be providing additional instrumental support to families of children with disabilities. Additional support may come instead from professionals and services (Findler, 2000).

Not surprising, perceived grandparent support was associated with frequency of contact and-to lesser extentresidential proximity. Increased frequency of contact provides more opportunity for support, either practically or emotionally. Given the cross-sectional nature of our data, we cannot rule out that this relationship may be operating in the opposite direction, specifically, that the higher levels of support necessitate increased contact.

To place the present results in context, next we discuss some of the methodological limitations of the study and also some implications for future research and clinical practice.

\section{Methodological Limitations}

There is good reason to be cautious about our findings and to plan for future replication of this research. First, the cumulative effect of response rates at various stages of the research indicates that the study sample was unlikely to have been representative of mothers of children with spina bifida. In particular, mothers with reasonably positive contact with their child's grandparents and mothers who were not under high levels of stress may have been the most likely to respond to the survey. Thus, differences may be evident at the extremes (e.g., grandparents may provide additional input to mothers of children with disabilities when the mothers are highly stressed). A second issue is that the recruitment method for the control sample of mothers was biased. The technique was used to increase the control of potentially salient demographic variables. However, there could well have been a systematic bias in the way the mothers chose to invite their friends to participate in the survey (again, perhaps friends with good relationships with grandparents and who were also not under high levels of stress).

\section{Directions for Future Research}

Assuming that the lack of an absolute difference in support from grandparents for mothers of children with and without disabilities is reliable, there are still several unanswered ques- tions about grandparent support in the context of families of children with disabilities. First, different types of disability (e.g., intellectual or cognitive disability) may be associated with different patterns of grandparent support. As suggested earlier, additional grandparent support might only be provided when families are under significant stress. Thus, group differences might be seen for mothers of children with severe intellectual disability, especially those who also exhibit significant behavioral problems. Of course, these suggestions are merely speculative at present, but it is important to explore these possibilities in more detail. A second issue is that grandparent support in control group designs to date has been measured in a fairly limited manner. In the current study no differences between groups were found for type of support (emotional vs. practical) provided by grandparents. A broader approach to measurement, however, may identify particular types of support that are provided more frequently by grandparents of children with disabilities.

Perhaps a more interesting, and practically important, question is whether grandparent support has different effects within families of children with and without disabilities. For example, parents of children with disabilities are likely to have smaller support networks than other parents (e.g., Kazak \& Wilcox, 1984). Under these circumstances, grandparent support may be more strongly related to parental well-being than in families where a broader range of support sources are available. If this is the case, clinicians may do well to develop methods of helping parents and grandparents maintain a positive support relationship to help protect parents from undue stress. At present, such an implication is conjecture, but the importance of conducting further research in this area is evident.

Finally, both the present study and Findler's (2000) focused on support provided to mothers of children with disabilities. Existing data suggest a potential difference in the impact that grandparent support might have for maternal and paternal well-being in families of children with disabilities (e.g., Baranowski \& Schilmoeller, 1999). Thus, it is important to assess whether fathers in families of children with disabilities receive more support than do fathers in other families. The same basic question might also be applied to siblings of children with disabilities. Qualitative research suggests that grandparents of children with disabilities perceive a part of their role as providing additional support to nondisabled siblings (Gardner et al., 1994). Thus, grandparents may well have more involvement with siblings in families of children with disabilities, and this could well be a factor that protects against the general risk of maladjustment in such children (Rossiter \& Sharpe, 2001).

\section{Implications for Clinical Practice}

The study has some important implications for professionals working with families of children with disabilities. Grandparents could play an important role in the provision of (emotional) support and practical help to these 
parents, and therefore alleviate parental distress. However, grandparents of children with disabilities are not more involved, compared with grandparents of children in the general population. One reason for this may be that grandparents need some sort of support themselves to cope with the reality of their grandchild's disability and do not have access to information regarding the child's condition (Hornby \& Ashworth, 1994; Meyer, 1993). These needs may diminish grandparents' emotional availability and their ability to provide support to parents at a time when they require it most. Professionals working with parents need to recognize and encourage grandparents as an integral part of the caregiver support system and may include grandparents in the intervention, education, and support related to the disability. Workshops and other programs have been developed to help grandparents accept the fact of their grandchild's disability and to provide informal support. In addition, the programs focus on how grandparents can support their families (e.g., George 1988; Vadasy et al., 1986). By addressing the needs of grandparents, professionals may also facilitate better intergenerational relationships and enable grandparents to demonstrate acceptance and provide emotional support to their children and grandchildren.

\section{References}

Baranowski, M. D. \& Schilmoeller, G. L. (1999). Grandparents in the lives of grandchildren with disabilities: Mothers' perceptions. Education and Treatment of Children, 22, 427-446.

Dunst, C., Trivette, C., \& Deal, A. (1996). Enabling and empowering families: Principles and guidelines for practice. Cambridge, MA: Brookline Books.

Findler, L. S. (2000). The role of grandparents in the social support system of mothers of children with a physical disability. Families in Society, 81, 370-381.

Findler, L., \& Taubman-Ben-Ari, O. (2003). Social workers' perceptions and practice regarding grandparents in families of children with a developmental disability. Families in Society, 84, 86-94.

Fuller-Thomson, E., Minkler, M., \& Driver, D. (1997). A profile of grandparents raising grandchildren in the United States. The Gerontologist, 37, 406-411.

Gardner, J. E., Scherman, A., Mobley, D., Brown, P., \& Schutter, M. (1994). Grandparents' beliefs regarding their role and relationship with special needs grandchildren. Education and Treatment of Children, 17, 185-196.

George, J. D. (1988). Therapeutic intervention for grandparents and extended family of children with developmental delays. Mental Retardation, 26, 369-375.

Glasberg, B. A., \& Harris, S. L. (1997). Grandparents and parents assess the development of their child with autism. Child and Family Behavior Therapy, 19, 17-27.

Grant, R. (2000). The special needs of children in kinship care. Journal of Gerontological Social Work, 33, 17-33.

Hastings, R. P. (1997). Grandparents of children with disabilities: A review. International Journal of Disability, Development and Education, 44, 329-340.

Hastings, R. P., Thomas, H., \& Delwiche, N. (2002). Grandparent support for families of children with Down syndrome. Journal of Applied Research in Intellectual Disabilities, 15, 97-104.

Heller, T., Hsieh, K., \& Rowitz, L. (2000). Grandparents as supports to mothers of persons with intellectual disability. Journal of Gerontological Social Work, 33, 23-34.

Hornby, G., \& Ashworth, T. (1994). Grandparents' support for families who have children with disabilities. Journal of Child and Family
Studies, 3, 403-412.

Kazak, A. E., \& Wilcox, B. L. (1984). The structure and function of social support networks in families with handicapped children. American Journal of Community Psychology, 12, 645-661.

Mayer, M. (2002). Grandparents raising grandchildren: Circumstances and interventions. School Psychology International, 23, 371-385.

Meyer, D. J. (1993). Lessons learned: Cognitive coping strategies of overlooked family members. In A. P. Turnbull, J. M. Patterson, S. K. Behr, D. L. Murphy, J. G. Marquis, \& M. J. Blue-Banning (Eds.), Cognitive coping, families and disability (pp. 81-93). Baltimore: Paul Brookes.

Mirfin-Veitch, B., Bray, A., \& Watson, M. (1996). "They really do care”: Grandparents as informal support sources for families of children with disabilities. New Zealand Journal of Disability Studies, 2, 136-148.

Mirfin-Veitch, B., Bray, A., \& Watson, M. (1997). "We're just that sort of family": Intergenerational relationships in families including children with disabilities. Family Relations, 46, 305-311.

Nybo, W. L., Scherman, A., \& Freeman, P. L. (1998). Grandparents' role in family systems with a deaf child. American Annals of the Deaf, 143, 260-267.

Pit-ten Cate, I. M., Kennedy, C. \& Stevenson, J. (2002). Disability and quality of life in spina bifida and hydrocephalus. Developmental Medicine and Child Neurology, 44, 317-322.

Rossiter, L., \& Sharpe, D. (2001). The siblings of individuals with mental retardation: A quantitative integration of the literature. Journal of Child and Family Studies, 10, 65-84.

Sandler, A. G. (1998). Grandparents of children with disabilities: A closer look. Education and Training in Mental Retardation and Developmental Disabilities, 33, 350-356.

Sandler, A. G., Warren, S. H., \& Raver, S. A. (1995). Grandparents as a source of support for parents of children with disabilities: A brief report. Mental Retardation, 33, 248-250.

Scherman, A., Gardner, J. E., Brown, P., \& Schutter, M. (1995). Grandparents' adjustment to grandchildren with disabilities. Educational Gerontology, 21, 261-273.

Schilmoeller, G. L., \& Baranowski, M. D. (1998). Intergenerational support in families with disabilities: Grandparents' perspectives. Families in Society, 79, 465-476.

Seligman, M., Goodwin, G., Paschal, K., Applegate, A., \& Lehman, L. (1997). Grandparents of children with disabilities: Perceived levels of support. Education and Training in Mental Retardation and Developmental Disabilities, 32, 293-303.

Stevenson, J. \& Pit-ten Cate, I.M. (2003). A study of the developmental, behavioural and psychological characteristics associated with hydrocephalus and spina bifida in middle childhood. Final report to the Association for Spina Bifida and Hydrocephalus.

Trute, B. (2003). Grandparents of children with developmental disabilities: Intergenerational support and family well-being. Families in Society, 84, 119-126.

Vadasy, P. F., Fewell, R. R., \& Meyer, D. J. (1986). Grandparents of children with special needs: Insights into their experiences and concerns. Journal of the Division for Early Childhood, 10, 36-44.

Waisbren, S. E. (1980). Parents' reactions after the birth of a developmentally disabled child. American Journal of Mental Deficiency, 84, 345-351.

Ineke M. Pit-ten Cate, $\mathrm{PhD}$, is a research fellow/tutor at the School of Psychology, University of Southampton. Richard P. Hastings, is professor, and Acting Head of School, School of Psychology, University of Wales Bangor. Hannah Johnson, BSc, School of Psychology, University of Southampton. Sara Titus, BSc, School of Psychology, University of Southampton. Correspondence regarding this article may be sent to the first author at ip@soton.ac.uk or School of Psychology, University of Southampton, Highfield, Southampton, SO17 1BJ, UK.

Manuscript received: December 3, 2004

Revised: April 7, 2005

Accepted: July 8, 2005 